\title{
Aqueous Barbier Allylation of Aldehydes Mediated by Tin
}

\author{
Ricardo L. Guimarães ${ }^{1,2, \dagger}$, Dimas J. P. Lima ${ }^{2}$, Maria Ester S. B. Barros ${ }^{2}$, Lívia N. Cavalcanti ${ }^{2}$, \\ Fernando Hallwass ${ }^{2}$, Marcelo Navarro ${ }^{2}$, Lothar W. Bieber ${ }^{2}$ and Ivani Malvestiti ${ }^{2, *}$
}

${ }^{1}$ Instituto de Ciências Ambientais e Desenvolvimento Sustentável, Universidade Federal da Bahia Campus Universitário Reitor Edgar Santos, Rua Professor José Seabra S/N - Barreiras - BA - 47805100, Brazil; ${ }^{\dagger}$ E-mail: riclima@ufba.br

2 Departamento de Química Fundamental, Universidade Federal de Pernambuco, Cidade Universitária, Recife-PE 50670- 901, Brazil

*Author to whom correspondence should be addressed; E-mail: ivani@ufpe.br, imalvestiti@gmail.com

Received: 16 June 2007; in revised form: 25 August 2007 / Accepted: 25 August 2007 / Published: 29 August 2007

\begin{abstract}
The aqueous tin-mediated Barbier reaction affords good to excellent yields and moderate syn diastereoselectivity under basic and acidic conditions. The high yields and stereoselectivity observed in the case of $o$-substituted aldehydes suggest a cyclic organotin intermediate or transition state in $\mathrm{K}_{2} \mathrm{HPO}_{4}$ solution. A practical and efficient aqueous tin allylation of methoxy- and hydroxybenzaldehydes can be carried out in $\mathrm{HCl}$ solution in 15 minutes to afford the corresponding homoallylic alcohols in high yields. Aliphatic aldehydes give moderate to excellent yields with reaction times ranging from 30 to 60 minutes. Under these conditions, crotylation gives exclusively the $\gamma$-product and the syn isomer is formed preferentially. For 2-methoxybenzaldehyde, an equilibration of the isomers to a syn/anti ratio of 1:1 can be observed after several hours. Control experiments with radical sources or scavengers give no support for radical intermediates. NMR studies suggest a mechanism involving an organotin intermediate. The major organotin species formed depends on the reaction medium and the reaction time. The use of acidic solution reduces the reaction times, due to the acceleration of the formation of the allyltin(IV) species.
\end{abstract}

Keywords: Fast Barbier reaction; hydroxy and methoxy benzaldehydes; aqueous; tin. 


\section{Introduction}

Carbonyl allylation is an important synthetic transformation in organic and pharmaceutical chemistry because the homoallylic alcohols produced are valuable synthetic intermediates [1]. The study of organometallic reactions using water as (co)-solvent has attracted renewed interest [1-2], mainly due to the increasing importance of environmentally friendly methodologies [3]. The Barbier reaction mediated by several metals such as zinc [4], tin [5], indium [6], manganese [7] and others [8], historically performed in anhydrous solvents, has been widely studied in aqueous media. Moreover, the use of water, an economically and environmentally benign solvent, reduces the need to handle flammable and anhydrous solvents and protection and deprotection processes are often unnecessary.

Although several groups have reported Barbier allylations of hydroxylated aldehydes, specially carbohydrates, in water [9], and a systematic study of hydroxy and methoxy aldehydes and ketones with tetrallyltin in toluene has been published [10], no data are available about the behavior of hydroxy and methoxy benzaldehydes in aqueous Barbier allylations. In general, tin-mediated allylation of carbonyl compounds has been reported as being a slow reaction, with reaction times ranging between 1 and 24 hours, depending on the substrate and reaction conditions [11]. Some attempts to improve yield and selectivity or to reduce the reaction time with the use of tin nanoparticles in water [12] or of an electrochemical process in water [13] have been reported.

In this work, we report the Barbier reaction mediated by tin in basic and acidic aqueous media with reaction times ranging from 15 minutes to 24 hours, according to the medium (Scheme 1).

Scheme 1. The Barbier type reaction in aqueous medium.

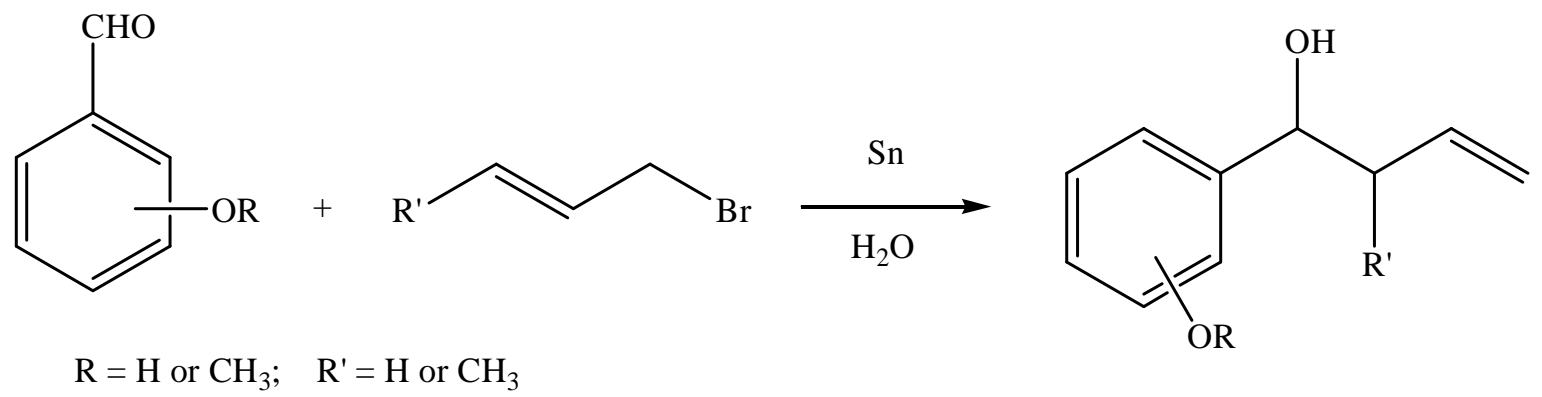

\section{Results and Discussion}

The initial tests were performed with 2-hydroxy and 2-methoxybenzaldehydes in water and basic solution $\left(\mathrm{K}_{2} \mathrm{HPO}_{4}\right)$, varying the reaction time. The best yields were achieved in 24 hours. Due to the importance of metallic salts in aqueous organometallic reactions [14] and previous unpublished results with the zinc mediated reaction, the catalyst, namely $\mathrm{Pb}(\mathrm{OAc})_{2}$, and solvents, alkaline solution $\left(\mathrm{K}_{2} \mathrm{HPO}_{4}\right)$ and pure water, were tested in the reaction with tin and allyl and crotyl bromide (Table 1). 
Table 1. Tin-mediated allylation of oxy-substituted benzaldehydes in aqueous media.

\begin{tabular}{|c|c|c|c|c|c|c|}
\hline Entry & Aldehyde & Halide & Salt added & Additive & Yield (\%) & Syn/anti ${ }^{\mathrm{a}}$ \\
\hline 1 & $2-\mathrm{CH}_{3} \mathrm{O}-\mathrm{C}_{6} \mathrm{H}_{4} \mathrm{CHO}$ & $\mathrm{C}_{3} \mathrm{H}_{5} \mathrm{Br}$ & - & - & 73 & - \\
\hline 2 & $2-\mathrm{CH}_{3} \mathrm{O}-\mathrm{C}_{6} \mathrm{H}_{4} \mathrm{CHO}$ & $\mathrm{C}_{3} \mathrm{H}_{5} \mathrm{Br}$ & $\mathrm{K}_{2} \mathrm{HPO}_{4}$ & - & 94 & - \\
\hline 3 & $4-\mathrm{CH}_{3} \mathrm{O}-\mathrm{C}_{6} \mathrm{H}_{4} \mathrm{CHO}$ & $\mathrm{C}_{3} \mathrm{H}_{5} \mathrm{Br}$ & $\mathrm{K}_{2} \mathrm{HPO}_{4}$ & - & 80 & - \\
\hline 4 & $3-\mathrm{CH}_{3} \mathrm{O}-\mathrm{C}_{6} \mathrm{H}_{4} \mathrm{CHO}$ & $\mathrm{C}_{3} \mathrm{H}_{5} \mathrm{Br}$ & $\mathrm{K}_{2} \mathrm{HPO}_{4}$ & - & 72 & - \\
\hline 5 & $3-\mathrm{CH}_{3} \mathrm{O}-\mathrm{C}_{6} \mathrm{H}_{4} \mathrm{CHO}$ & $\mathrm{C}_{3} \mathrm{H}_{5} \mathrm{Br}$ & - & - & 84 & - \\
\hline 6 & $2-\mathrm{HO}-\mathrm{C}_{6} \mathrm{H}_{4} \mathrm{CHO}$ & $\mathrm{C}_{3} \mathrm{H}_{5} \mathrm{Br}$ & - & - & 61 & - \\
\hline 7 & 2-HO- $\mathrm{C}_{6} \mathrm{H}_{4} \mathrm{CHO}$ & $\mathrm{C}_{3} \mathrm{H}_{5} \mathrm{Br}$ & $\mathrm{K}_{2} \mathrm{HPO}_{4}$ & - & 85 & - \\
\hline 8 & $3-\mathrm{HO}-\mathrm{C}_{6} \mathrm{H}_{4} \mathrm{CHO}$ & $\mathrm{C}_{3} \mathrm{H}_{5} \mathrm{Br}$ & $\mathrm{K}_{2} \mathrm{HPO}_{4}^{\mathrm{b}}$ & - & 43 & - \\
\hline 9 & $3-\mathrm{HO}-\mathrm{C}_{6} \mathrm{H}_{4} \mathrm{CHO}$ & $\mathrm{C}_{3} \mathrm{H}_{5} \mathrm{Br}$ & $\mathrm{K}_{2} \mathrm{HPO}_{4}^{\mathrm{b}}$ & $\mathrm{Pb}(\mathrm{OAc})_{2}$ & 60 & - \\
\hline 10 & $4-\mathrm{HO}-\mathrm{C}_{6} \mathrm{H}_{4} \mathrm{CHO}$ & $\mathrm{C}_{3} \mathrm{H}_{5} \mathrm{Br}$ & $\mathrm{K}_{2} \mathrm{HPO}_{4}{ }^{\mathrm{b}}$ & - & 25 & - \\
\hline 11 & $4-\mathrm{HO}-\mathrm{C}_{6} \mathrm{H}_{4} \mathrm{CHO}$ & $\mathrm{C}_{3} \mathrm{H}_{5} \mathrm{Br}$ & $\mathrm{K}_{2} \mathrm{HPO}_{4}^{\mathrm{b}}$ & $\mathrm{Pb}(\mathrm{OAc})_{2}$ & 71 & - \\
\hline 12 & 2- $\mathrm{CH}_{3} \mathrm{O}-\mathrm{C}_{6} \mathrm{H}_{4} \mathrm{CHO}$ & $\mathrm{C}_{4} \mathrm{H}_{7} \mathrm{Br}$ & $\mathrm{K}_{2} \mathrm{HPO}_{4}$ & - & 98 & $65: 35$ \\
\hline 13 & $3-\mathrm{CH}_{3} \mathrm{O}-\mathrm{C}_{6} \mathrm{H}_{4} \mathrm{CHO}$ & $\mathrm{C}_{4} \mathrm{H}_{7} \mathrm{Br}$ & $\mathrm{K}_{2} \mathrm{HPO}_{4}$ & - & 98 & $50: 50$ \\
\hline 14 & $4-\mathrm{CH}_{3} \mathrm{O}-\mathrm{C}_{6} \mathrm{H}_{4} \mathrm{CHO}$ & $\mathrm{C}_{4} \mathrm{H}_{7} \mathrm{Br}$ & - & - & 80 & $50: 50$ \\
\hline 15 & $2-\mathrm{HO}-\mathrm{C}_{6} \mathrm{H}_{4} \mathrm{CHO}$ & $\mathrm{C}_{4} \mathrm{H}_{7} \mathrm{Br}$ & $\mathrm{K}_{2} \mathrm{HPO}_{4}$ & - & 84 & $70: 30$ \\
\hline 16 & $3-\mathrm{HO}-\mathrm{C}_{6} \mathrm{H}_{4} \mathrm{CHO}$ & $\mathrm{C}_{4} \mathrm{H}_{7} \mathrm{Br}$ & $\mathrm{K}_{2} \mathrm{HPO}_{4}$ & - & 88 & $55: 45$ \\
\hline 17 & 4-HO- $\mathrm{C}_{6} \mathrm{H}_{4} \mathrm{CHO}$ & $\mathrm{C}_{4} \mathrm{H}_{7} \mathrm{Br}$ & $\mathrm{K}_{2} \mathrm{HPO}_{4}$ & - & 72 & $57: 43$ \\
\hline
\end{tabular}

${ }^{a}$ The syn:anti ratio was determined using the ${ }^{1} \mathrm{H}-\mathrm{NMR}$ signal areas for the methyl group of the homoallylic alcohols. ${ }^{\mathrm{b}}$ Dioxane $(0.2 \mathrm{~mL})$ was used as co-solvent.

The Barbier reaction afforded good yields with 2-methoxybenzaldehyde and 2-hydroxybenzaldehyde in water (entries 1 and 6), which increased in alkaline solution (entries 2 and 7). With 4methoxybenzaldehyde the best result was achieved in $\mathrm{K}_{2} \mathrm{HPO}_{4}$ solution (entry 3), while 3-methoxybenzaldehyde, on the other hand, yielded better results in pure water (entries 4 and 5).

The hydroxylated aldehydes, except for 2-hydroxybenzaldehde (entry 7), gave best yields using $\mathrm{Pb}(\mathrm{OAc})_{2}$ as a catalyst (entries 9 and 11). Other metallic salts were also tested, but their presence only decreased the reaction yields. The next step was the Barbier reaction with crotyl bromide (Table 1), where, in addition to the reactivity, the diastereoselectivity was analyzed. In these reactions, both 2and 3-methoxybenzaldehyde gave excellent yields in alkaline media (entries 12 and 13), and 4methoxybenzaldehyde gave $80 \%$ of addition product (entry 14) in pure water. A similar behavior was observed for hydroxybenzaldehydes, with yields ranging between $72-88 \%$ (entries 15 - 17). In all these cases, no additive was necessary. Regarding the diastereoselectivity, only low syn selectivity was observed with ortho substituted aldehydes, affording ratios of 65:35 for 2-methoxybenzaldehyde (entry 12) and 70:30 for 2-hydroxybenzaldehyde (entry 15). The use of additives did not improve the yields or the diastereoselectivity. Even though the literature explained the syn diastereoselectivity via an acyclic intermediate $[15,16]$, in these particular cases the presence of a coordinating group in the ortho position could favor a cyclic transition state (Figure 1), as previously proposed in the literature [17]. This could explain the observed increase in the diastereoselectivity only with the ortho substituted aldehydes, suggesting a probable allyltin species as intermediate. 
Figure 1. A cyclic transition state.

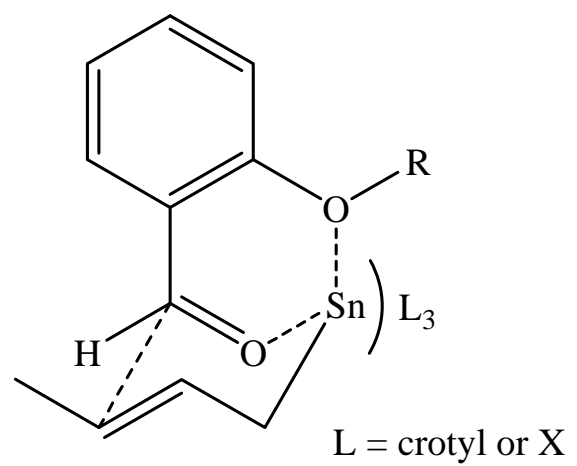

The experimental conditions developed afforded good yields for the Barbier reaction, but the diastereoselectivity was still low and observed only with ortho substituted benzaldehydes, therefore new conditions were pursued in order to reduce the reaction times and increase the diastereoselectivity. Initially, it was suggested that use of acidic conditions might be beneficial due to enhancement of carbonyl reactivity. Hydrochloric acid solution, normally used for quenching the reaction, was tested and it reduced the reaction times to only one minute. When no acid solution was added, almost all the aldehyde was recovered. The allylation of aromatic and aliphatic aldehydes with allyl bromide using tin in acid solution at room temperature are shown in Table 2.

Table 2. Allylation of aromatic and aliphatic aldehydes with allyl bromide mediated by tin in acid solution at room temperature.

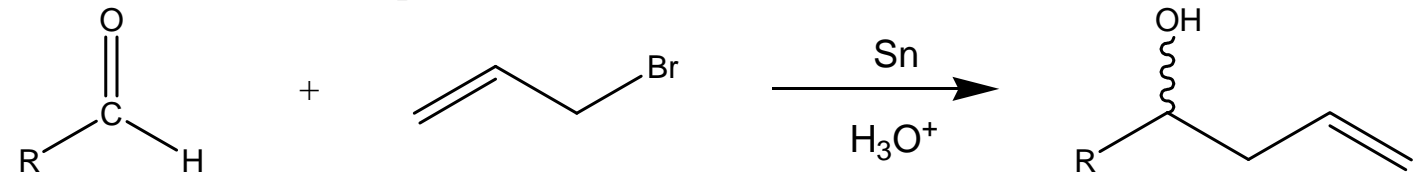

\begin{tabular}{|c|c|c|c|c|}
\hline Entry & Aldehyde & Acid solution & Time (min) & Yield (\%) \\
\hline $1^{\mathrm{a}}$ & $2-\mathrm{OCH}_{3}-\mathrm{C}_{6} \mathrm{H}_{4} \mathrm{CHO}$ & $\mathrm{HCl}$ & 5 & 97 \\
\hline $2^{a}$ & $2-\mathrm{OCH}_{3}-\mathrm{C}_{6} \mathrm{H}_{4} \mathrm{CHO}$ & $\mathrm{H}_{2} \mathrm{SO}_{4}$ & 5 & 98 \\
\hline $3^{a}$ & $2-\mathrm{OCH}_{3}-\mathrm{C}_{6} \mathrm{H}_{4} \mathrm{CHO}$ & $\mathrm{HNO}_{3}$ & 5 & 94 \\
\hline $4^{\mathrm{a}}$ & $2-\mathrm{OCH}_{3}-\mathrm{C}_{6} \mathrm{H}_{4} \mathrm{CHO}$ & $\mathrm{CF}_{3} \mathrm{CO}_{2} \mathrm{H}$ & 5 & 78 \\
\hline $5^{\mathrm{a}}$ & $\mathrm{C}_{6} \mathrm{H}_{5} \mathrm{CHO}$ & $\mathrm{HCl}$ & 5 & 93 \\
\hline $6^{\mathrm{a}}$ & $3-\mathrm{OCH}_{3}-\mathrm{C}_{6} \mathrm{H}_{4} \mathrm{CHO}$ & $\mathrm{HCl}$ & 5 & 98 \\
\hline $7^{\mathrm{a}}$ & $2-\mathrm{OH}-\mathrm{C}_{6} \mathrm{H}_{4} \mathrm{CHO}$ & $\mathrm{HCl}$ & 5 & 98 \\
\hline $8^{a}$ & $3-\mathrm{OH}-\mathrm{C}_{6} \mathrm{H}_{4} \mathrm{CHO}$ & $\mathrm{HCl}$ & 5 & 41 \\
\hline $9^{\mathrm{a}, \mathrm{b}}$ & $3-\mathrm{OH}-\mathrm{C}_{6} \mathrm{H}_{4} \mathrm{CHO}$ & $\mathrm{HCl}$ & 60 & 54 \\
\hline $10^{\mathrm{a}}$ & $3,4-\left(\mathrm{OCH}_{3}\right)_{2}-\mathrm{C}_{6} \mathrm{H}_{3} \mathrm{CHO}$ & $\mathrm{HCl}$ & 5 & 99 \\
\hline $11^{\mathrm{a}}$ & $3-\mathrm{OH}-4-\mathrm{OCH}_{3}-\mathrm{C}_{6} \mathrm{H}_{3} \mathrm{CHO}$ & $\mathrm{HCl}$ & 5 & 60 \\
\hline $12^{\mathrm{a}}$ & $\mathrm{n}-\mathrm{C}_{6} \mathrm{H}_{13} \mathrm{CHO}$ & $\mathrm{HCl}$ & 30 & 90 \\
\hline $13^{\mathrm{a}}$ & $\left(\mathrm{CH}_{3}\right)_{2} \mathrm{CHCHO}$ & $\mathrm{HCl}$ & 60 & 30 \\
\hline $14^{\mathrm{c}}$ & $\mathrm{C}_{6} \mathrm{H}_{5} \mathrm{CHO}$ & $\mathrm{HCl}$ & 15 & 92 \\
\hline $15^{\mathrm{c}}$ & $2-\mathrm{OCH}_{3}-\mathrm{C}_{6} \mathrm{H}_{4} \mathrm{CHO}$ & $\mathrm{HCl}$ & 15 & 95 \\
\hline $16^{\mathrm{c}}$ & $3-\mathrm{OCH}_{3}-\mathrm{C}_{6} \mathrm{H}_{4} \mathrm{CHO}$ & $\mathrm{HCl}$ & 15 & 96 \\
\hline
\end{tabular}


Table 2. Cont.

\begin{tabular}{rlccc}
\hline Entry & Aldehyde & Acid solution & Time (min) & Yield (\%) \\
\hline $17^{c}$ & $4-\mathrm{OCH}_{3}-\mathrm{C}_{6} \mathrm{H}_{4} \mathrm{CHO}$ & $\mathrm{HCl}$ & 15 & 86 \\
$18^{c}$ & $4-\mathrm{F}-\mathrm{C}_{6} \mathrm{H}_{4} \mathrm{CHO}$ & $\mathrm{HCl}$ & 15 & 88 \\
$19^{c}$ & $2-\mathrm{OH}-\mathrm{C}_{6} \mathrm{H}_{4} \mathrm{CHO}$ & $\mathrm{HCl}$ & 15 & 70 \\
$20^{c}$ & $2-\mathrm{OH}-3-\mathrm{OCH}_{3}-\mathrm{C}_{6} \mathrm{H}_{3} \mathrm{CHO}$ & $\mathrm{HCl}$ & 15 & 80 \\
$21^{c}$ & $3-\mathrm{OH}-4-\mathrm{OCH}_{3}-\mathrm{C}_{6} \mathrm{H}_{3} \mathrm{CHO}$ & $\mathrm{HCl}$ & 15 & 85 \\
$22^{c}$ & $3,4-\left(\mathrm{OCH}_{3}\right)_{2}-\mathrm{C}_{6} \mathrm{H}_{3} \mathrm{CHO}$ & $\mathrm{HCl}$ & 15 & 92 \\
$23^{c}$ & $\mathrm{C}_{6} \mathrm{H}_{5}\left(\mathrm{CH}_{2}\right)_{2} \mathrm{CHO}$ & $\mathrm{HCl}$ & 15 & 65 \\
\hline
\end{tabular}

a Aldehyde $(0.2 \mathrm{mmol})$, allyl bromide $(0.75 \mathrm{mmol})$, tin $(0.5 \mathrm{mmol})$ in $1.0 \mathrm{~mol} \mathrm{~L}{ }^{-1} \mathrm{HCl}(2.0 \mathrm{~mL})$.

${ }^{\mathrm{b}}$ Dioxane was used as co-solvent. ${ }^{\mathrm{c}}$ Aldehyde $(0.5 \mathrm{mmol})$, allyl bromide $(0.6 \mathrm{mmol})$, tin $(0.5$ $\mathrm{mmol})$ in $0.25 \mathrm{~mol} \mathrm{~L}^{-1} \mathrm{HCl}(2.0 \mathrm{~mL})$.

Other acid solutions, such as $\mathrm{H}_{2} \mathrm{SO}_{4}, \mathrm{HNO}_{3}, \mathrm{HBr}$ and $\mathrm{CF}_{3} \mathrm{CO}_{2} \mathrm{H}$, were tested at several concentrations and volumes, as well as several stirring times and all of them showed similar results, probably due to a general acid catalysis or acid activation of the metal surface. Allylation of benzaldehyde and methoxybenzaldehydes afforded homoallylic alcohols in excellent yields (entries 1 - 6). Allylation of 2-hydroxybenzaldehyde and 3,4-dimethoxybenzaldehyde produced also excellent yields (entries 7 and 10). 3-Hydroxy-4-methoxybenzaldehyde gave only a moderate yield (entry 11). For 3-hydroxybenzaldehyde, even after 1 hour of reaction, only a moderate yield was obtained (entries 8 and 9). Under the same conditions, 4-hydroxybenzaldehyde afforded only traces of product. Aliphatic aldehydes needed longer reaction times - 30 minutes for heptanaldehyde, with excellent yield (entry 12), and 1 hour for isobutyraldehyde, giving a low yield (entry 13). No aldehyde was recovered in any of the reactions. In these heterogeneous reactions efficient stirring was an important parameter for their success and reproducibility.

The initial tests were performed using excess of halide (3.2 equivalents) and concentrated acid solutions $\left(1.0 \mathrm{~mol} \mathrm{~L}^{-1}\right.$, entries 1 - 13) with excellent yields and 5 minutes reaction times. In order to reduce the waste of starting materials the ratio of aldehyde, halide and metal was modified. The best results were obtained in 15 minutes and using aldehyde, halide and tin in the ratio of 1:1.2:1 (entries 14 - 23), except for the aliphatic aldehydes and for 3-OH and 4-OH-benzaldehyde, whose yields decreased significantly. In order to evaluate the regio- and stereoselectivity, we also studied these conditions using crotyl bromide. The results of allylation of aromatic and aliphatic aldehydes with crotyl bromide using tin in $\mathrm{HCl}$ solution at room temperature are presented in Table 3. Crotylation occurred exclusively in the $\gamma$-position, with excellent yields with all aromatic aldehydes (entries $1-8$ ). The aliphatic heptanaldehyde afforded a good yield after 1 hour (entry 9). Reducing the excess of crotyl halide and tin led to a significant decrease of the reaction yields, except with 3-phenylpropanal, benzaldehyde, 4-fluorbenzaldehyde, 2-methoxy and 2-hydroxybenzaldehyde, where excellent results were obtained (entries $10-14$ ).

It was observed that the syn/anti selectivity improved in comparison with some results published in the literature, in either organic or aqueous media [4b, 16b, 18]. Some examples on the literature had 
diastereoselectivity higher than 7:3, but in some cases the anti isomer was the major product [1b, 16a, 19].

Table 3. Allylation of aromatic and aliphatic aldehydes with crotyl bromide mediated by tin in $\mathrm{HCl}$ solution at room temperature.

\begin{tabular}{clccc} 
& & & & \\
\hline
\end{tabular}

a The syn:anti ratio was determined by ${ }^{1} \mathrm{H}-\mathrm{NMR}$. ${ }^{\mathrm{b}}$ Aldehyde $(0.2 \mathrm{mmol})$, crotyl bromide (0.75 mmol), tin $(0.5 \mathrm{mmol})$ in $1.0 \mathrm{~mol} \mathrm{~L}{ }^{-1} \mathrm{HCl}(2.0 \mathrm{~mL}) .{ }^{\mathrm{c}}$ Aldehyde $(0.5 \mathrm{mmol})$, crotyl bromide $(0.6 \mathrm{mmol})$, tin $(0.5 \mathrm{mmol})$ in $0.25 \mathrm{~mol} \mathrm{~L}^{-1} \mathrm{HCl}(2.0 \mathrm{~mL})$.

Other experiments were performed in $1.0 \mathrm{~mol} \mathrm{~L}^{-1} \mathrm{HCl}$ solution with 2-methoxybenzaldehyde, where the reaction time was increased and a decrease of the diastereoselectivity was observed (entries 2, 15 and 16), suggesting the presence of an equilibration process under these reaction conditions. This equilibration could be explained by a symmetric oxonia-Cope type rearrangement or a solvolysis process [20, 21].

Comparing the two sets of data, the reaction in acid medium presents good to excellent yields with reduced reaction times for aromatic and aliphatic aldehydes and moderated syn diastereoselectivity for all cases. The reaction performed in basic medium presents good yields and moderated syn diastereoselectivity only for aldehydes containing the ortho chelating group. Therefore the reaction pathways should be distinct in basic and acidic conditions. 
Regarding the mechanism of the Barbier reaction, the literature proposes three different mechanisms involving a single electron transfer (SET), a radical-anion formation or an organometallic reagent [1a]. The prevailing mechanism usually depends upon the metal, substrates and reaction conditions. Moyano and co-workers have described a theoretical study of the Barbier reaction, where the proposed mechanism involves a SET process [22]. This transference will be dependent upon the electron affinities (EA) of the reactants, since the radical anion preferably formed will be that derived from the species with higher EA [22-23]. In the Barbier reaction, the aromatic carbonyl compounds will have the largest EA, thus forming a radical anion. In addition, the reduction potential (E) of the aldehyde can influence its reactivity [7]. The measured reduction potential of the aldehydes and the calculated EA's are presented in Table 4.

Table 4. Reduction potential (E) and electron affinity (EA) of substituted benzaldehydes and allyl bromide.

\begin{tabular}{cccc}
\hline Entry & Reagent & EA (kcal mol $\left.\mathbf{~ m}^{\mathbf{1}}\right)$ & E (V) \\
\hline 1 & $\mathrm{C}_{6} \mathrm{H}_{5} \mathrm{CHO}$ & 24.7 & -1.36 \\
2 & $2-\mathrm{HO}-\mathrm{C}_{6} \mathrm{H}_{4} \mathrm{CHO}$ & 28.8 & -1.48 \\
3 & $3-\mathrm{HO}-\mathrm{C}_{6} \mathrm{H}_{4} \mathrm{CHO}$ & 27.8 & -1.68 \\
4 & $4-\mathrm{HO}-\mathrm{C}_{6} \mathrm{H}_{4} \mathrm{CHO}$ & 26.1 & -2.14 \\
5 & $2-\mathrm{CH}_{3} \mathrm{O}-\mathrm{C}_{6} \mathrm{H}_{4} \mathrm{CHO}$ & 27.4 & -1.55 \\
6 & $3-\mathrm{CH}_{3} \mathrm{O}-\mathrm{C}_{6} \mathrm{H}_{4} \mathrm{CHO}$ & 28.3 & -1.50 \\
7 & $4-\mathrm{CH}_{3} \mathrm{O}-\mathrm{C}_{6} \mathrm{H}_{4} \mathrm{CHO}$ & 26.3 & -1.64 \\
8 & $\mathrm{CH}_{2}=\mathrm{CHCH}_{2} \mathrm{Br}$ & 3.21 & $-1.73^{\mathrm{a}}$ \\
\hline
\end{tabular}

${ }^{\mathrm{a}}$ See reference [23].

Considering the results shown in Tables 1 through 4, there is no direct correlation between the observed yields and the reduction potentials or the electron affinities. Nevertheless, the reduction potential can be used to rationalize the reactivity of the aromatic aldehydes, as lower reaction yields were obtained with 3-OH and 4-OH-benzaldehydes, which have the more negative reduction potentials (entries 3 and 4), which suggest a lower reactivity of the carbonyl compound. However, in acid medium, the lower yields could also be related to the fact that these two aldehydes are solids and almost insoluble in water, requiring dioxane as co-solvent. In basic medium, the yields with 3-OH and 4-OH-benzaldehydes were moderated to good (Table 1, entries 9, 11, 16 and 17), and in these cases the solubility should increase due to the formation of anionic species.

In order to obtain some mechanistic information, additional tests were performed with a radical initiator, dibenzoyl peroxide, and radical scavengers, phenol and 2,2,6,6-tetramethylpiperidine- $N$-oxyl (TEMPO) in $\mathrm{K}_{2} \mathrm{HPO}_{4}$ solution. For all the aldehydes examined, including unsubstituted benzaldehyde, very small variations, within the reproducibility of the reaction, were observed with all addictives. These results turn a radical and anion-radical chain mechanism less probable because neither radical initiators (peroxide) nor scavengers (phenol, TEMPO) had significant influence in the reaction [24].

In addition to these results, that are the unchanged behavior in the presence of radical initiators and inhibitors, the observation of small amounts of tetrallyltin at the end of our reactions in basic medium 
and the syn diastereoselectivity only for 2-substituted benzaldehydes, suggest that the mechanism involves organometallic species.

A mechanism involving an organometallic intermediate was already proposed by Whitesides, Marshall and Chan [9, 25, 26]. Recently, Chan et al. carried out a theoretical study of hydrolysis and carbonyl additions reactions for a series of allylmetals in gas phase [27]. The divalent metal allyl complexes of group 14 have similar reactivity toward hydrolysis and carbonyl addition. On the order hand, tetravalent group 14 metals form $\sigma$-complexes with allyl ligands and these complexes are less reactive toward hydrolysis than toward allylation. These results indicated that allyl complexes of tetravalent metals, such as allyl- $\mathrm{SnBr}_{3}$, are suitable for allylation in aqueous media.

Establishing a mechanism involving organotin species in aqueous medium is a challenging task, since only $\mathrm{SnX}_{4}$, with $\mathrm{X}=$ halides, in water yields a complex equilibrium whose species and concentrations depend upon the $\mathrm{pH}$ and halide nature.[28] For organotin species, these equilibria should be even more complex, since they can undergo hydrolysis and ligand exchanges [29].

As a result, an effort was undertaken to identify and characterize the predominant species responsible for the observed results. Initially the progress of the reaction of allyl bromide, metallic tin and benzaldehyde in pure water was monitored by extracting samples with $\mathrm{CDCl}_{3}$, followed by ${ }^{1} \mathrm{H}$ NMR analysis.

Figure 2. Partial ${ }^{1} \mathrm{H}$-NMR spectra in $\mathrm{CDCl}_{3}$ of the reaction of allyl bromide and tin in water after extraction. a) 15 minutes; b) 30 minutes; c) 1 h, d) 4 h and e) 8 h. Assignments: allyl bromide (I); tetrallyltin (II); triallyltin bromide (III); diallyltin dibromide (IV) and propene (V).
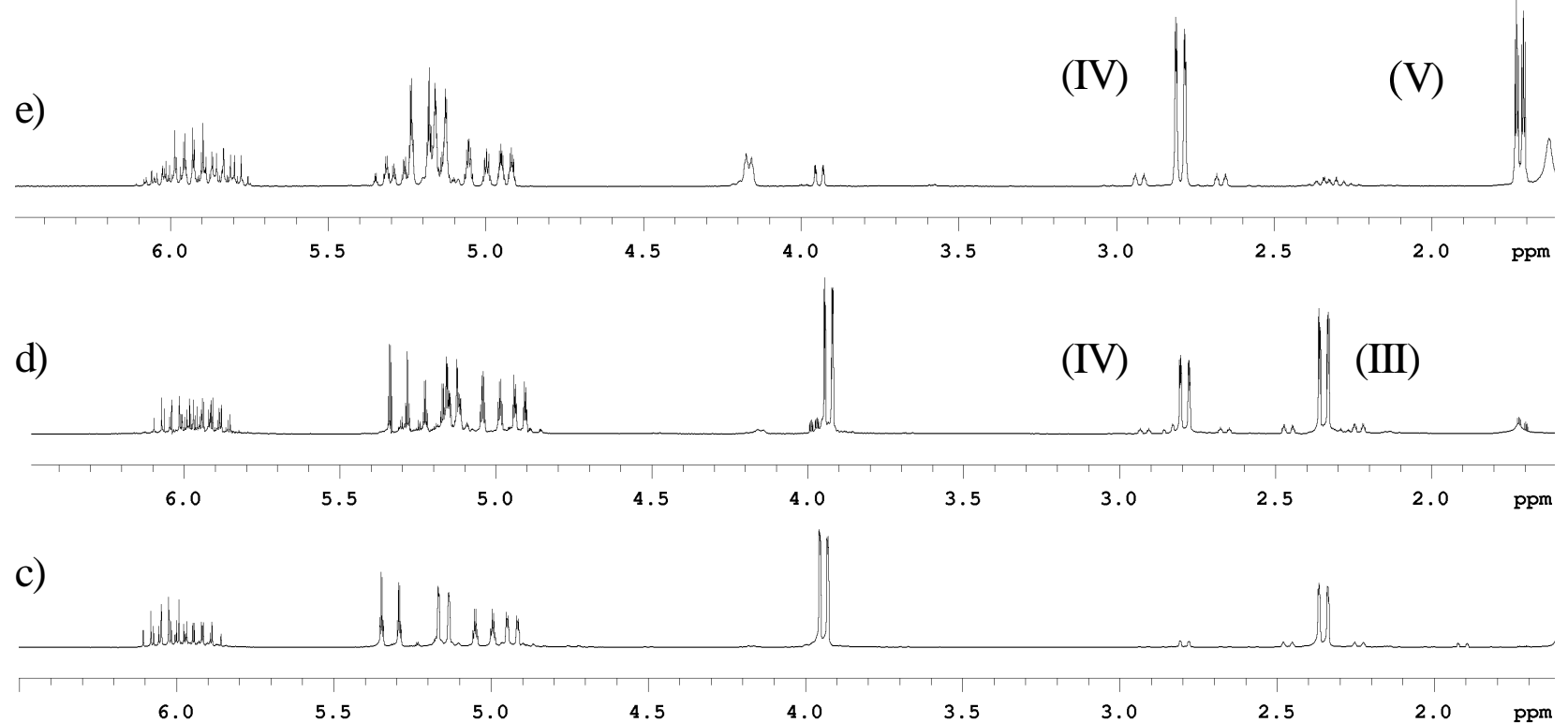

b)

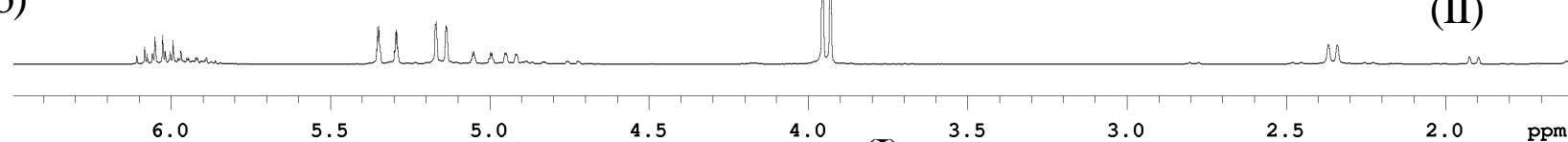

(II)

a)

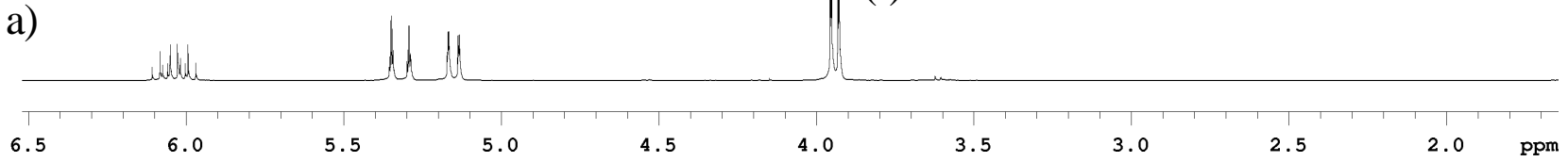

(I) 
Nonetheless, organotin species were observed only after the benzaldehyde was consumed. Consequently, the monitoring was also carried out in the absence of aldehyde, and the formation of organotin was observed in water, acidic and basic conditions. The reaction was carried out at room temperature in $\mathrm{K}_{2} \mathrm{HPO}_{4}$ solution and samples of the reaction mixture $(1 \mathrm{~mL})$ were extracted with $\mathrm{CDCl}_{3}$ (containing anisole as internal standard) at different time intervals and monitored by ${ }^{1} \mathrm{H}-\mathrm{NMR}$. The only species observed in low concentration at $1.9 \mathrm{ppm}$ and ${ }^{2} J_{\mathrm{H}-\mathrm{Sn}}=63 \mathrm{~Hz}$ was characterized based upon the literature ${ }^{1} \mathrm{H}-\mathrm{NMR}$ data as tetrallyltin [30]. The allylation reaction was also tested using commercial tetrallyltin and 2-methoxybenzaldehyde in $\mathrm{K}_{2} \mathrm{HPO}_{4}$ solution, which after 6 hours afforded the homoallylic alcohol in $70 \%$ yield. Theses results indicate that the organotin formation in $\mathrm{K}_{2} \mathrm{HPO}_{4}$ solution was very slow, what could explain the need for such long reaction times.

However, the $\mathrm{CDCl}_{3}$ extraction could leave behind water soluble allyltin species in the aqueous media; therefore the reaction was also performed in $\mathrm{D}_{2} \mathrm{O}$. First of all, the ${ }^{1} \mathrm{H}$-NMR spectrum of a commercial sample of tetrallyltin was obtained in $\mathrm{D}_{2} \mathrm{O}$, but it has low solubility, almost generating two phases what did not allowed a clear assignment of the H-Sn coupling constant. The ${ }^{119} \mathrm{Sn}$ spectrum was then obtained and a signal at $-44 \mathrm{ppm}$ was observed, which could be used to determine the presence of tetrallyltin. When the reaction of allyl bromide and tin was performed with $\mathrm{K}_{2} \mathrm{HPO}_{4}$ in $\mathrm{D}_{2} \mathrm{O}$, the metal is partially or totally consumed depending on the reaction time, generating a grey suspension whose ${ }^{1} \mathrm{H}-\mathrm{NMR}$ spectrum was hard to analyze due to quite broad signals. The ${ }^{119} \mathrm{Sn}$-NMR spectrum was not conclusive, since no tetrallyltin was observed and only a broad signal at $-530 \mathrm{ppm}$ was observed, a chemical shift characteristic of inorganic tin salts. After extraction with $\mathrm{CDCl}_{3}$ containing cyclohexane as an internal standard, $70 \%$ of tetrallyltin was recovered, suggesting that this is the main species generated under these conditions. Considering the difficulties to analyze the reaction in $\mathrm{D}_{2} \mathrm{O}$ and the lack of ${ }^{119} \mathrm{Sn}-\mathrm{NMR}$ data in $\mathrm{D}_{2} \mathrm{O}$ for the allyltin species, we continued the NMR studies in $\mathrm{CDCl}_{3}$.

The reaction performed in water was also monitored by ${ }^{1} \mathrm{H}-\mathrm{NMR}$, after extraction with $\mathrm{CDCl}_{3}$, and formation of organotin was observed only after 30 minutes of vigorous stirring. The species initially observed had chemical shift of $1.9 \mathrm{ppm}$ and ${ }^{2} J_{\mathrm{H}-\mathrm{Sn}}=63 \mathrm{~Hz}$, in agreement with data for tetrallyltin. The samples monitored after longer reaction times showed the formation of other species at $2.4 \mathrm{ppm}\left({ }^{2} J_{\mathrm{H}-\mathrm{Sn}}\right.$ $=68 \mathrm{~Hz})$ and $2.8 \mathrm{ppm}\left({ }^{2} J_{\mathrm{H}-\mathrm{Sn}}=77 \mathrm{~Hz}\right)$, as shown in Figure 2 . A change in the pH of the solution was also observed during the progress of the reaction from 6 to approximately 1, after 30 minutes.

To our knowledge, the only ${ }^{1} \mathrm{H}-\mathrm{NMR}$ data available for allyltin(IV) bromides in the literature are assigned to diallyltin dibromide [26]. However, in our experiments we observed tetrallyltin and two other organotin compounds.

Naruta et. al describe the ${ }^{1} \mathrm{H}$ - and ${ }^{119} \mathrm{Sn}$-NMR spectra of allyltin (IV) chlorides prepared by the Kocheshkov redistribution reaction involving tetrallyltin and $\mathrm{SnCl}_{4}$ [30]. Based upon the chemical shifts and coupling constants of allyltin (IV) chlorides, [30, 31] the doublets at $2.4 \mathrm{ppm}\left({ }^{2} J_{\mathrm{H}-\mathrm{Sn}}=68 \mathrm{~Hz}\right)$ and 2.8ppm $\left({ }^{2} J_{\mathrm{H}-\mathrm{Sn}}=77 \mathrm{~Hz}\right)$ were assigned to the triallyltin bromide and diallyltin dibromide species, respectively. Another experiment was performed in order to corroborate these assignments. It is known that the addition of $\mathrm{HX}$ or $\mathrm{X}_{2}$ can be used to break the tin-carbon bonds yielding an alkane as byproduct. [30] Therefore, $\mathrm{HBr}$ (50\% in water) was added dropwise to tetrallyltin in deuterated chloroform and monitored by ${ }^{1} \mathrm{H}$-NMR. The same species obtained previously were observed at 2.4ppm, 2.8ppm and 3.2ppm $\left({ }^{2} J_{\mathrm{H}-\mathrm{Sn}}=105.6 \mathrm{~Hz}\right)$, respectively, as presented in Figure 3. 
Figure 3. Partial ${ }^{1} \mathrm{H}-\mathrm{NMR}$ spectra in $\mathrm{CDCl}_{3}$ of the reaction of tetrallyltin with $\mathrm{HBr}(\mathrm{aq})$. (a) tetrallyltin; (b) first addition; (c) second addition, d) third addition. Assignments: tetrallyltin (II); triallyltin bromide (III); diallyltin dibromide (IV), propene (V) and allyltin tribromide (VI).
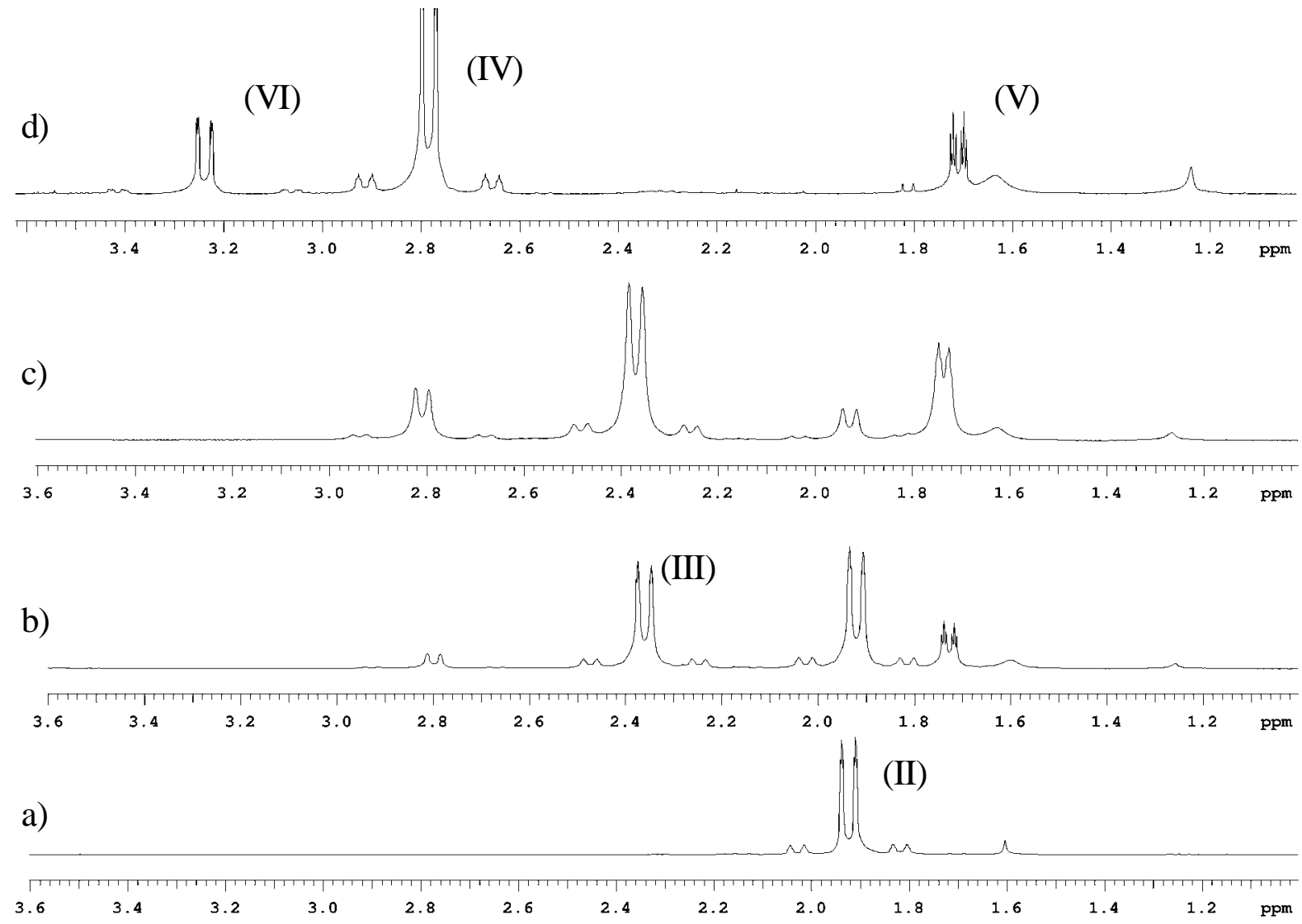

After the characterization of allyltin(IV) bromide species in $\mathrm{CDCl}_{3}$, the reaction of allyl bromide and tin was performed in aqueous solutions of $\mathrm{HCl}$ and $\mathrm{HNO}_{3}$ (Figure 4). In these cases, significant formation of tetrallyltin and triallyltin bromide was observed after five minutes and most of the allyl bromide was consumed within 30 minutes and practically only one species giving a signal at 2.4ppm remained present, namely triallyltin bromide. The same compound was observed in the reactions performed in water, $\mathrm{HCl}$ and $\mathrm{HNO}_{3}$ aqueous solution, but the formation of this species was faster in acidic media than in pure water. 
Figure 4. Partial ${ }^{1} \mathrm{H}-\mathrm{NMR}$ spectra in $\mathrm{CDCl}_{3}$ of the reaction of allyl bromide and metallic tin in $\mathrm{HNO}_{3}$ solution. a) 5 minutes; b) 15 minutes; c) 30 minutes. Assignments: allyl bromide (I), tetrallyltin (II); triallyltin bromide (III).

c)

b)

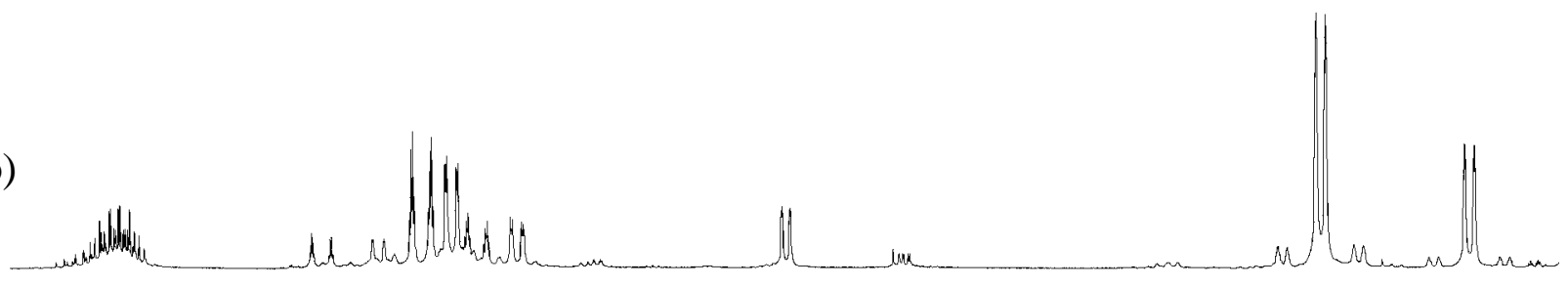

a)

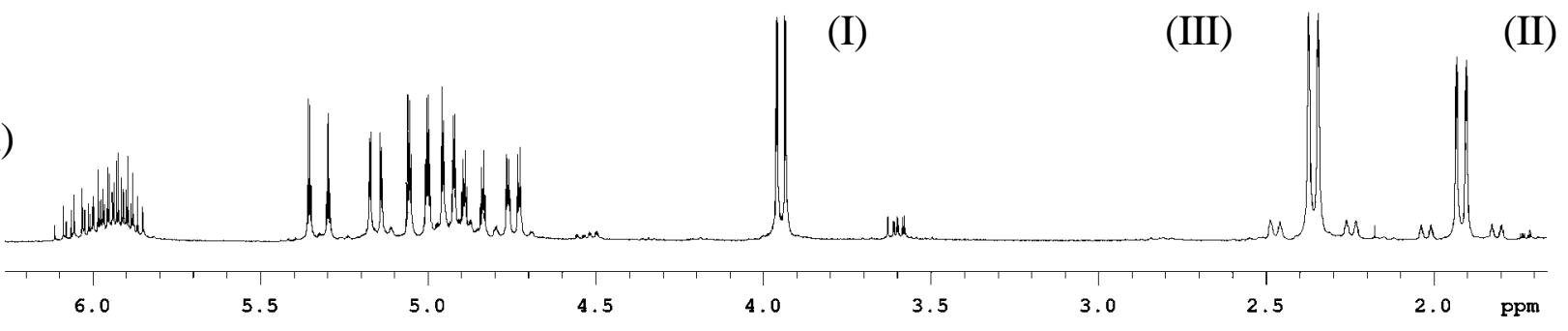

The reactivity of tetrallyltin and triallyltin bromide was probed by adding to the $\mathrm{CDCl}_{3}$ solution small amounts of benzaldehyde followed by immediate ${ }^{1} \mathrm{H}$-NMR analysis as presented in Figure 5. It is clear that triallyltin bromide was consumed first suggesting that it is more reactive than tetrallyltin.

The formation of organotin(IV) halide species is probably the rate-determining step; therefore, the increase of the rate for the organometallic formation would decrease the allylation reaction times. Since HX can cleave Sn-C bonds, the carbonyl addition step should also be faster than the organotin decomposition in order to explain the observed high yields for the allylation reaction.

\section{Conclusions}

In summary, systematic studies of the aqueous Barbier allylations of hydroxy- and methoxysubstituted benzaldehydes mediated by tin were reported. The reactions exhibited good to excellent yields when mediated by tin in basic and in acidic medium, without the need to protect $\mathrm{OH}$ groups. Even though, the reaction yields were good to excellent in the majority of the aldehydes, the excess of halide and tin could be reduced only in the acid conditions, which also had the advantage of the shorter 
reaction times. Considering the short reaction time, the ratio 1:1.2:1 aldehyde, halide and tin for several methoxy- and hydroxybenzaldehydes and even for some aliphatic aldehydes, the acid conditions seem quite promising for preparative purposes. For the aliphatic aldehydes, the yields are moderate to excellent and reaction times ranging from 30 to 60 minutes. To our knowledge, the present reaction times are the shortest obtained for the tin-mediated Barbier allylations. In addition, the reactions were carried out under mild and convenient conditions, and no additive (except the $\mathrm{HCl}$ solution), no inert atmosphere was needed.

Figure 5: Partial ${ }^{1} \mathrm{H}-\mathrm{NMR}$ spectra in $\mathrm{CDCl}_{3}$ of the reaction of benzaldehyde and the tetrallyltin and triallyltin bromide mixture. a) Before addition of the aldehyde; b) first addition of benzaldehyde; c) second addition. Assignments: tetrallyltin (II); triallyltin bromide (III) and alcohol homoallylic (VII).

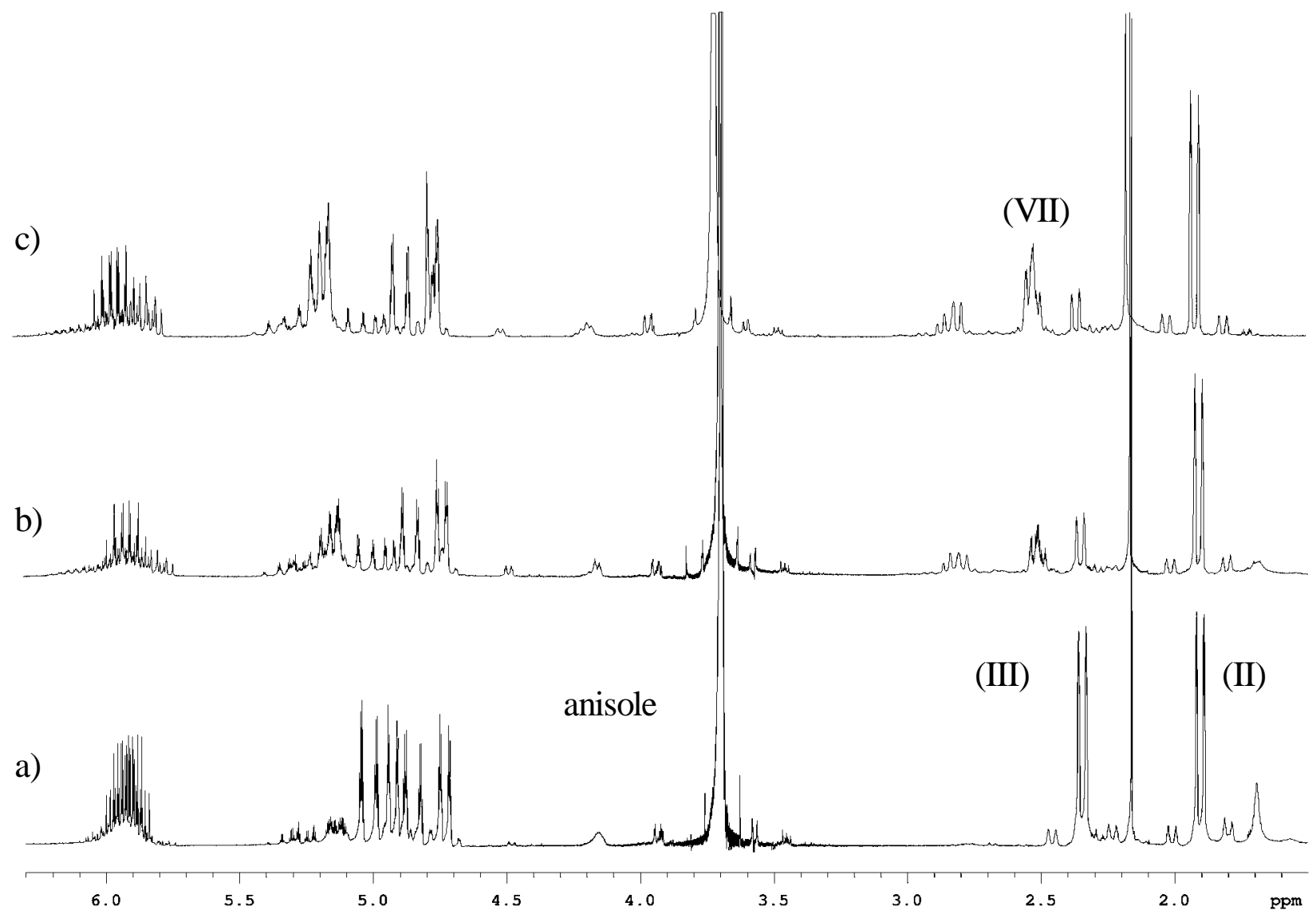

Regarding the mechanism of the Barbier reaction mediated by tin, the experiments using radical initiators and inhibitors suggested that it should not involve a single electron transfer (SET), but more likely it should involve an organotin intermediate. The NMR studies suggest that the organotin formed depend upon the $\mathrm{pH}$, where in basic conditions the major species observed was the tetrallyltin even after $24 \mathrm{~h}$ reactions. On the other hand, under acidic conditions more than one species was observed, and their reactivity seems quite different. Furthermore, the decrease of the reaction times is due to the use of acid solution that acts as a catalyst for the allyltin(IV) bromide formation. As for the selectivity, 
the $\gamma$-product is obtained exclusively in crotylation, and the syn isomer is formed preferentially within a few minutes. An increase of the reaction time for 2-methoxybenzaldehyde led to a decrease of the syn/anti selectivity due to an equilibration process.

\section{Experimental}

\section{General}

All solvents and reagents were commercially available and used without further purification. Tin powder 325 mesh (99.8\%) from Acros Organics was used. ${ }^{1} \mathrm{H}-\mathrm{NMR}$ (300 MHz), ${ }^{13} \mathrm{C}-\mathrm{NMR}$ (75 MHz) and ${ }^{119} \mathrm{Sn}(111.8 \mathrm{MHz})$ spectra were recorded on a VARIAN UNITY PLUS-300 instrument. Chemical shifts $(\delta)$ are reported in parts per million (ppm) relative to tetramethylsilane (TMS) as an internal standard to ${ }^{1} \mathrm{H}$ and ${ }^{13} \mathrm{C}$ spectra and coupling constants $(J)$ are given in hertz $(\mathrm{Hz})$. Neat $\mathrm{SnCl}_{4}$ at 148ppm used as ${ }^{119}$ Sn NMR standard. All products were known and their physical and spectroscopic data were compared with those of authentic samples.

\section{General procedure for the Barbier reaction mediated by tin under basic conditions}

Allyl halide $(1.0 \mathrm{mmol})$, tin $(0.5 \mathrm{mmol})$ and catalyst $(0.06 \mathrm{mmol}$, when indicated) were added to aldehyde $(0.2 \mathrm{mmol})$ water or saturated solution of $\mathrm{K}_{2} \mathrm{HPO}_{4}(2 \mathrm{~mL})$ at $30^{\circ} \mathrm{C}$. After 24 hours under vigorous stirring, the mixture was acidified with $2 \mathrm{~mol} \mathrm{~L}^{-1} \mathrm{HCl}$ and extracted with $\mathrm{CHCl}_{3}\left(\right.$ or $\mathrm{CDCl}_{3}$ ) $(1 \mathrm{~mL})$ containing cyclohexane $(0.05 \mathrm{mmol})$ as internal quantitative standard. The extracts were analyzed directly by ${ }^{1} \mathrm{H}-\mathrm{NMR}$.

\section{General procedure for the Barbier reaction mediated by tin under acidic conditions}

Aldehyde $(0.5 \mathrm{mmol})$, allyl or crotyl bromide $(0.6 \mathrm{mmol})$ and tin $(0.5 \mathrm{mmol})$ in $\mathrm{HCl}(2.0 \mathrm{~mL}, 0.25$ mol L ${ }^{-1}$ ) were stirred at $30^{\circ} \mathrm{C}$ for the indicated time and then extracted with $\mathrm{CHCl}_{3}$ (or $\left.\mathrm{CDCl}_{3}\right)(1 \mathrm{~mL})$ containing cyclohexane (or anisole) as internal quantitative reference. The extracts were analyzed directly by ${ }^{1} \mathrm{H}-\mathrm{NMR}$.

\section{Procedure for the organotin intermediate formation}

Tin powder $(2.0 \mathrm{mmol})$ and allyl bromide $(4.0 \mathrm{mmol})$ in saturated $\mathrm{K}_{2} \mathrm{HPO}_{4}$ solution $(4 \mathrm{~mL})$ were vigorous stirred at $30^{\circ} \mathrm{C}$. Samples of the reaction mixture $(1 \mathrm{~mL})$ were extracted with $\mathrm{CDCl}_{3}$ (containing anisole as internal standard) in different time intervals and monitored by ${ }^{1} \mathrm{H}$ - and ${ }^{119} \mathrm{Sn}$ NMR. 
Reaction between 2-methoxybenzaldehyde and tetrallyltin

2-Methoxybenzaldehyde $(0.3 \mathrm{mmol})$ and tetrallyltin $(0.15 \mathrm{mmol})$ were added to saturated $\mathrm{K}_{2} \mathrm{HPO}_{4}$ solution $(2.0 \mathrm{~mL})$ and vigorously stirred at $30^{\circ} \mathrm{C}$. After $6 \mathrm{~h}$ the reaction mixture was extracted with $\mathrm{CDCl}_{3}$ (containing anisole as internal standard) and analyzed by ${ }^{1} \mathrm{H}-\mathrm{NMR}$.

\section{Measurement of the reduction potential and electron affinity calculations}

The reduction potential measurements were obtained by cyclic voltammetry, using vitreous carbon as the working electrode, $\mathrm{Pt}$ as auxiliary electrode and $\mathrm{Ag} / \mathrm{AgCl}\left(3 \mathrm{~mol} \mathrm{~L}^{-1} \mathrm{KCl}\right)$ as reference electrode and $\mathrm{CH}_{3} \mathrm{CN}$ as solvent. The electron affinities were calculated as the energy difference between the radical-anion and the neutral molecule, both at the neutral geometry, with the AM1 method.

\section{Acknowledgements}

This work was supported by CNPq, CAPES and FACEPE. Special thanks are due to Professor Ricardo L. Longo for his help on the electron affinity calculations.

\section{References and Notes}

1. (a) Li, C. J. Aqueous Barbier-Grignard Type Reaction: Scope, Mechanism, and Synthetic Applications. Tetrahedron, 1996, 52, 5643-5668; (b) Tan, X. H.; Hou, Y. Q.; Huang, C.; Liu, L.; Guo, Q. X. SnCl 2 -mediated carbonyl allylation in fully aqueous media. Tetrahedron 2004, 60, 6129-6136; (c) Tan, K. T.; Chng, S. S.; Cheng, H. S.; Loh, T. P. Development of a Highly $\alpha-$ Regioselective Metal-Mediated Allylation Reaction in Aqueous Media: New Mechanistic Proposal for the Origin of $\alpha$-Homoallylic Alcohols. J. Am. Chem. Soc. 2003, 125, 2958-2963; (d) Nicolau, K. C.; Ninchovic, S.; Sarabia, F.; Vourloumis, D.; He, Y.; Vallberg, H.; Finlay, M. R. V.; Yang, Z. Total Syntheses of Epothilones A and B via a Macrolactonization-Based Strategy. J. Am. Chem. Soc. 1997, 119, 7974-7991.

2. (a) Li, C. J. Organic Reactions in Aqueous Media with a Focus on Carbon-Carbon Bond Formations: A Decade Update. Chem. Rev. 2005, 105, 3095-3165; (b) Li, C. J.; Chan, T. H. Organic Reactions in Aqueous Media; John Wiley \& Sons: New York, 1997.

3. Anastas, P. T.; Kirchhoff, M. M. Origins, Current Status, and Future Challenges of Green Chemistry. Acc. Chem. Res. 2002, 35, 686-694.

4. (a) Petrier, C.; Luche, J. L. Allylzinc reagents additions in aqueous media. J. Org. Chem. 1985, 50, 910-912; (b) Marton, D.; Stivanello, D.; Tagliavini, G. Study of the Allylation of Aldehydes with Allyl Halides in Cosolvent/Water(Salt)/Zn and in Cosolvent/Water(Salt)/Zn/Haloorganotin Media. J. Org. Chem. 1996, 61, 2731-2737; (c) Chung, W.; Higashiya, S.; Oba, Y.; Welch, J. Indium and zinc-mediated allylation of difluoroacetyltrialkylsilanes in aqueous media. Tetrahedron 2003, 59, 10031-10036. (d) Lu, W. S.; Chan, T. H. Organometallic Reactions in 
Aqueous Media. Indium and Zinc-Mediated Allylation of Sulfonimines. J. Org. Chem. 2000, 65, 8589-8594.

5. (a) Nokami, J.; Otera, J.; Sudo, T.; Okawara, R. Allylation of aldehydes and ketones in the presence of water by allylic bromides, metallic tin, and aluminum. Organometallics 1983, 2, 191193; (b) Zhou, J. Y.; Chen, Z. G.; Wu, S. H. Tin-promoted stereocontrolled intramolecular allylation of carbonyl-compounds - a facile and stereoselective method for ring construction. Chem. Commun. 1994, 2783-2784.

6. (a) Chan, T. H.; Li, C. J.; Lee, M. C.; Wei, Z. Y. 1993 Ru-Lemieux-Award-Lecture Organometallic-type Reactions in Aqueous-Media - A New Challenge in Organic-Synthesis. Can.

J. Chem. 1994, 72, 1181-1192; (b) Paquette, L. A.; Mitzel, T. M. Addition of Allylindium Reagents to Aldehydes Substituted at $\mathrm{C} \alpha$ or $\mathrm{C} \beta$ with Heteroatomic Functional Groups. Analysis of the Modulation in Diastereoselectivity Attainable in Aqueous, Organic, and Mixed Solvent Systems. J. Am. Chem. Soc. 1996, 118, 1931-1937; c) Chan, Y. H.; Yang, Y. J. Indium-Mediated Organometallic Reactions in Aqueous Media: The Nature of the Allylindium Intermediate. J. Am. Chem. Soc. 1999, 121, 3228-3229.

7. Li, C. J.; Meng, Y.; Yi, X. H. Manganese-Mediated Carbon-Carbon Bond Formation in Aqueous Media: Chemoselective Allylation and Pinacol Coupling of Aryl Aldehydes. J. Org. Chem. 1998, 63, 7498-7504.

8. (a) Miyamoto, H.; Daikawa, N.; Tanaka, K. Carbon-carbon bond formation using bismuth in a water medium. Tetrahedron Lett. 2003, 44, 6963-6964; (b) Chan, T. C.; Lau, C. P.; Chan, T. H. Iron-mediated allylation of aryl aldehydes in aqueous media. Tetrahedron Lett. 2004, 45, 41894191.

9. Schimd, W.; Whitesides, G. M. Carbon-carbon bond formation in aqueous ethanol: diastereoselective transformation of unprotected carbohydrates to higher carbon sugars using allyl bromide and tin metal. J. Am. Chem. Soc. 1991, 113, 6674-6675.

10. Yasuda, M.; Fujibayashi, T.; Baba, A. Allylation of Carbonyl Compounds Bearing a Hydroxyl Group by Tetraallyltin: Highly Stereoselective Allylation in a Chelation-Controlled Manner. J. Org. Chem. 1998, 63, 6401-6404.

11. Wang, Z.; Zha, Z.; Zhou, C. Application of Tin and Nanometer Tin in Allylation of Carbonyl Compounds in Tap Water Org. Lett. 2002, 4, 1683-1685.

12. Zha, Z.; Qiao, S. Q.; Jiang, J.; Wang, Y.; Miao, Q.; Wang, Z. Barbier-type reaction mediated with tin nano-particles in water. Tetrahedron 2005, 61, 2521-2527.

13. Zha, Z.; Hui, A.; Zhou, Y.; Miao, Q.; Wang, Z.; Zhang, H. A Recyclable Electrochemical Allylation in Water. Org. Lett. 2005, 7, 1903-1905.

14. (a) Takahara, J. P.; Masuyama, Y.; Kumsu, Y. Palladium-catalyzed carbonyl allylation by allylic alcohols with stannous chloride. J. Am. Chem. Soc. 1992, 114, 2577-2586; b) Bieber, L. W.; Malvestiti, I.; Storch, E. C. Reformatsky Reaction in Water: Evidence for a Radical Chain Process. J. Org. Chem. 1997, 62, 9061-9064. (c) Lannou, M. I.; Hélion, F.; Namy, J. L. Catalytic Barbier-type reactions of lactones and esters mediated by the Mischmetall/SmI 2 (cat.) $s y s t e m$ or the

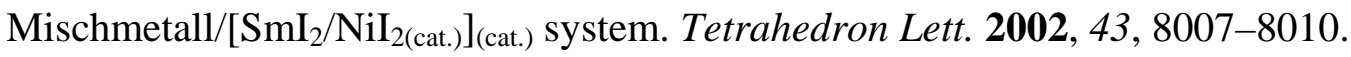

15. Wada, M.; Ohki, H.; Akiba, K. -Y. Bismuth(III) Chloride Aluminum-promoted Allylation of Aldehydes to Homoallylic Alcohols in Aqueous Solvent. Bull. Chem. Soc. Jpn. 1990, 1738-1747. 
16. (a) Yamamoto, Y.; Yatagai, H.; Naruta, Y.; Maruyama, K. Erythro-selective addition of crotyltrialkyltins to aldehydes regardless of the geometry of the crotyl unit. Stereoselection independent of the stereochemistry of precursors. J. Am. Chem. Soc. 1980, 102, 7107-7109; (b) Zha, Z.; Quiao, S. Q.; Jiang, J.; Wang, Y.; Miao, Q.; Wang, Z. Barbier-type reaction mediated with tin nano-particles in water. Tetrahedron 2005, 61, 2521-2527.

17. (a) Paquette, L.A.; Mitzel, T.M. Comparative diastereoselectivity analysis of crotylindium and 3bromoallylindium additions to $\alpha$-oxy aldehydes in aqueous and nonaqueous solvent systems, $J$. Org. Chem. 1996, 61, 8799-8804; (b) Chung, W., Chan, T. H. Indium-mediated organometallic reactions in aqueous media. Stereoselectivity in crotylation of sulfonimines bearing a proximal chelating group. J. Org. Chem. 2001, 66, 3467-3473.

18. Furlani, D.; Marton, D.; Tagliavini, G.; Zordan, M. Hydrated sigma-bonded organometallic cations in organic-synthesis. 1. allyl-stannation, crotyl-stannation, 1-methylallyl-stannation, cyclohex-2-enyl-stannation, and cinnamyl-stannation of carbonyl-compounds in water. $J$. Organomet. Chem. 1988, 341, 345-356.

19. Sinha, P.; Roy, S. Barbier Reaction in the Regime of Metal Oxide: Carbonyl Allylation over $\mathrm{SnO} / \mathrm{Cu}_{2} \mathrm{O}$ and Surface Diagnostics. Organometallics 2004, 23, 67-71.

20. Crosby, S. R.; Harding, J. R.; King, C. D.; Parker, G. D.; Willis, C. L. Oxonia-Cope Rearrangement and Side-Chain Exchange in the Prins Cyclization. Org. Lett. 2002, 4, 577-580.

21. Jasti, R.; Rychnovsky, S. D.; Racemization in Prins Cyclization Reactions. J. Am. Chem. Soc. 2006, 128, 13640-13648.

22. Moyano, A.; Pericàs, M. A.; Riera, A.; Luche, J. L. A theoretical study of the Barbier reaction. Tetrahedron Lett. 1990, 31, 7619-7622.

23. Bard, A.J; Merz, A. Electrochemical reduction of allyl halides in nonaqueous solvents - a reinvestigation. J. Am. Chem. Soc. 1979, 101, 2959-2965.

24. (a) Beckwith, A. L. J.; Bowry, V. W.; Ingold, K. U. Kinetics of nitroxide radical trapping. 1. Solvent effects. J. Am. Chem. Soc. 1992, 114, 4983-4992; b) Bowry, V. W.; Ingold, K. U. Kinetics of nitroxide radical trapping. 2. Structural effects. J. Am. Chem. Soc. 1992, 114, 49924996.

25. Marshall, J. A.; Hinkle, K. W. Synthesis of anti-Homoallylic Alcohols and Monoprotected 1,2Diols through $\mathrm{InCl}_{3}$-Promoted Addition of Allylic Stannanes to Aldehydes. J. Org. Chem. 1995, 60, 1920-1921.

26. Chan, T. H.; Yang, Y.; Li, C. J. Organometallic Reactions in Aqueous Media. The Nature of the Organotin Intermediate in the Tin-Mediated Allylation of Carbonyl Compounds. J. Org. Chem. 1999, 64, 4452 - 4455.

27. Chung, L. W.; Chan, T. H.; Wu, Y.D. Theoretical study of Intrinsic reactivities of various allylmetals toward carbonyl and water. Organometallics 2005, 24, 1598-1607.

28. Taylor, M. J.; Coddington, J. M. The constitution of aqueous tin(IV) chloride and bromide solutions and solvent extracts studied by ${ }^{119}$ Sn NMR and vibrational spectroscopy. Polyhedron 1992, 11, 1531-1544.

29. Thoonen, S. H. L.; Deelman, B. J.; Koten, G. Synthetic aspects of tetraorganotins and organotin(IV) halides. J. Organomet. Chem. 2004, 689, 2145-2157. 
30. Naruta, Y.; Nishigaichi, Y.; Maruyam, K. NMR study on transmetalation reaction between allyltins and $\mathrm{SnCl}_{4}$. Tetrahedron 1989, 45, 1067-1078.

31. Petrosyan, V.S. NMR-spectra and structures of organotin compounds Prog. NMR Spectrosc. 1977, 11, 115-148.

Sample Availability: Samples of all the compounds are available from authors.

(C) 2007 by MDPI (http://www.mdpi.org). Reproduction is permitted for noncommercial purposes. 